\section{Traffic-related air pollution: an avoidable exposure to improve respiratory health}

\author{
Peter D Sly
}

Respiratory disease taken as a whole is a major global burden contributing significantly to morbidity and mortality at all stages of life. According to WHO estimates, asthma is the most prevalent respiratory condition with over 300 million people affected globally and an additional 100 million diagnoses forecast by 2025 . The second most prevalent condition is COPD, with an estimated 210 million suffering globally. Pneumonia and acute lower respiratory illnesses are the leading causes of death in children under 5 years of age, responsible for an estimated 1.4 million deaths annually. It is currently understood that low lung function is a major risk factor linking all these entities, increasing susceptibility to these global health problems.

Lung function is known to track throughout childhood, ${ }^{1}{ }^{2}$ so to a very real extent the lung function one is born with is a major determinant of future respiratory health. $^{3-5}$ However, lung function may grow better ${ }^{6}$ or less well ${ }^{7-9}$ than anticipated depending on environmental exposures, especially those occurring in early life. Airway branching pattern develops during the first 16-18 weeks of fetal development, with alveolar development beginning later and continuing in early postnatal life. Thus, the respiratory system is vulnerable to adverse environmental exposures in both prenatal and postnatal life. The most compelling data for prenatal exposures influencing lung function at birth ${ }^{10}$ and beyond ${ }^{11}$ are for fetal exposure to tobacco smoking, especially from the mother smoking during pregnancy. However, other prenatal exposures to environmental toxicants are thought to limit respiratory development in utero, as exemplified by maternal exposures to household chemicals during pregnancy. ${ }^{12}$ There are two potential pathways by which prenatal exposures might result in low lung function at birth; by direct effects on lung development or via effects on somatic growth of the fetus. Birth weight has a

Correspondence to Peter D Sly, Children's Health and Environment Program, Queensland Children's Medical Research Institute, The University of Queensland, Royal Children's Hospital, 300 Herston Rd, Brisbane, QLD 4029, Australia; p.sly@uq.edu.au small but significant direct effect on adult lung function, independent of factors known to influence adult lung function, including parental and personal heights and tobacco smoking. ${ }^{13}$ However, to date, the direct effects of prenatal exposures on lung function are presumptive as no study has been conducted using a technique that directly measures airway calibre or airway mechanics at or soon after birth.

Morales et $\mathrm{al}^{14}$ report on the effects of intrauterine and early postnatal exposure to ambient air pollution on lung function in preschool-aged children (mean age 4.5 years). They have used sophisticated modelling to estimate individual exposures to benzene and nitrogen dioxide to indicate exposure to traffic-related pollution and found significant reductions in $\mathrm{FEV}_{1}$ with both pollutants. A dose-response relationship was demonstrated with the risk of low lung function, defined as $\mathrm{FEV}_{1}$ $<80 \%$ predicted, increasing with increasing pollutant exposures. In addition, Morales et $a l^{14}$ were able to demonstrate that the effects of exposure were most pronounced during the second trimester. These data are credible and consistent with previous reports of maternal exposures to ambient air pollution decreasing fetal somatic growth ${ }^{15}$ and infant lung function measured during tidal breathing. ${ }^{16}$ Hansen et $a l,{ }^{15}$ using less sophisticated modelling of pollution exposure than used by Morales et al, ${ }^{14}$ also showed that effects of exposures varied during gestation; however, in their study the impacts were more variable. There are also numerous reports of the adverse effects of ambient air pollution, either from traffic-related or industrial sources, on lung function in older children. ${ }^{9} 1718$ What the study from Morales et $a l^{14}$ adds to the literature is the increased precision of the exposure estimates and the age of the children studied. They provide convincing evidence that prenatal exposures to traffic-related pollution have long-term effects on lung function in otherwise healthy children.

Despite the value of this study, it does have limitations. The model validation used passive samplers distributed over the study area, rather than in the individual children's homes and the exposure estimates were averaged over various periods (annual, pregnancy and each trimester) to represent mean levels for each period. There are no data on which to judge whether such mean levels better represent the potential for 'damage' than peak levels, the number of occasions above a threshold value or some type of integrated exposure, such as area under an exposure-time curve. Clearly personal monitoring in a study of the scope (both in time frame and in numbers of subjects studies) undertaken by Morales et $\mathrm{al}^{14}$ would not be possible and they have probably done as much as they could. Another limitation is the use of spirometry in preschool-aged children. This test is not easy to perform in young children and indeed, as shown in their Table 2, Morales et $a l^{14}$ were only able to obtain reproducible spirometry in fewer than $50 \%$ of the children tested. Another issue with spirometry in this age group is the physiological interpretation of $\mathrm{FEV}_{1}$. The utility and validity of standard spirometry performed during maximal forced expiration are that expiratory flow limitation is induced so that the flow obtained is independent of effort and, as such, reflects the mechanical properties of the airways and lungs. However, young children are unlikely to be able to maintain flow limitation to very low lung volumes; this is likely to be one of the reasons for the normal fall in $\mathrm{FEV}_{1} / \mathrm{FVC}$ ratio reported through childhood. ${ }^{19}$ The $\mathrm{FEV}_{1} / \mathrm{FVC}$ ratio reported by Morales et $\mathrm{al}^{14}$ of $93 \%-94 \%$ is normal for this age range, ${ }^{20}$ but very different from the $80 \%$ that is taken to be the lower limit of normal in older children or adults. Young children's lungs are essentially empty within $1 \mathrm{~s}$ and thus $\mathrm{FEV}_{1}$ and the $\mathrm{FEV}_{1} / \mathrm{FVC}$ ratio need to be interpreted differently in young children. Morales et $a l^{14}$ may have been better to have measured lung function with the forced oscillation technique, which has both a higher success rate in young children and measures the mechanical properties of airways and lungs with a similar physiological interpretation in all ages, with the exception of infants measured via a face mask where the impedance of the nasal pathways is also included.

Despite the study limitations, Morales et $a l^{14}$ should be lauded for producing convincing data in a large number of children highlighting the long-term consequences of exposure to traffic-related pollution and the lifelong increased risk of respiratory disease. This exposure is potentially avoidable and can be influenced by regulation and legislation. Policy makers need to heed data such as those presented by Morales et $a l^{14}$ as limiting exposure to traffic-related pollution during fetal 
development and early postnatal life is one way that the burden of respiratory disease can be decreased.

Competing interests None.

Provenance and peer review Not commissioned; internally peer reviewed.

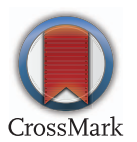

To cite Sly PD. Thorax 2015;70:3-4.

Published Online First 20 October 2014

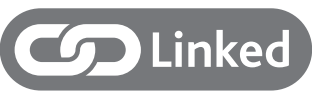

- http://dx.doi.org/10.1136/thoraxjnl-2014-205413

Thorax 2015:70:3-4.

doi:10.1136/thoraxjnl-2014-206227

\section{REFERENCES}

1 Hibbert ME, Hudson IL, Lanigan A, et al. Tracking of lung function in healthy children and adolescents. Pediatr Pulmonol 1990;8:172-7.

2 Hopper JL, Hibbert ME, Macaskill GT, et al. Longitudinal analysis of lung function growth in healthy children and adolescents. J Appl Physiol 1991;70:770-7.
3 Turner SW, Palmer LJ, Rye PJ, et al. Infants with flow limitation at 4 weeks: outcome at 6 and 11 years. Am J Respir Crit Care Med 2002;165:1294-8.

4 Young S, Arnott J, O'Keeffe P, et al. The association between early life lung function and wheezing during the first 2 years of life. Eur Respir J 2000;15:151-7.

5 Murray CS, Pipis SD, McArdle EC, et al. Woodcock A on behalf of the National Asthma Campaign Manchester Asthma and Allergy Study Group. Lung function at one month of age as a risk factor for infant respiratory symptoms in a high risk population. Thorax 2002:57:388-92.

6 Woodcock A, Lowe LA, Murray CS, et al. on behalf of the NAC Manchester Asthma and Allergy Study Group. Early life environmental control: effect on symptoms, sensitization, and lung function at age 3 years. Am J Respir Crit Care Med 2004;170:433-9.

7 Belgrave DCM, Buchan I, Bishop C, et al. Trajectories of lung function during childhood. Am J Respir Crit Care Med 2014;189:1101-9.

8 Calderon-Garciduenas L, Mora-Tiscareno A, Fordham LA, et al. Respiratory damage in children exposed to urban pollution. Pediatr Pulmonol 2003;36:148-61.

9 Gauderman WJ, Avol E, Gilliland F, et al. The effect of air pollution on lung development from 10 to 18 years of age.[see comment][erratum appears in $\mathrm{N}$ Engl J Med 2005 Mar 24;352(12):1276]. N Engl J Med 2004;351:1057-67.

10 Stick SM, Burton PR, Gurrin L, et al. Effects of maternal smoking during pregnancy and a family history of asthma on respiratory function in newborn infants. Lancet 1996;348:1060-4.

11 Le Souef PN. Paediatric origins of adult lung diseases 4: tobacco related lung diseases begin in childhood. Thorax 2000;55:1063-7.
12 Henderson J, Sherriff A, Farrow A, et al. Household chemicals, persistent wheezing and lung function: effect modification by atopy? Eur Respir J 2008:31:547-54.

13 Suresh S, Manun A, O'Callaghan M, et al. The impact of birth weight on peak lung function in young adults. Chest 2012;142:1603-10.

14 Morales E, Garcia-Estaban R, de la Cruz OA, et al. Intrauterine and early postnatal exposure to outdoor air pollution and lung function at preschool age. Thorax 2015;70:64-73.

15 Hansen C, Barnett A, Pritchard G. The effect of ambient air pollution during ealy pregnancy on fetal ultrasonic measurements during mid-pregnancy. Environ Health Perspect 2008;116:362-9.

16 Latzin P, Roosli M, Huss A, et al. Air pollution during pregnancy and lung function in newborns: a birth cohort study. Eur Respir J 2009;33: 594-603.

17 Wichmann FA, Müller A, Busi LE, et al. Increased asthma and respiratory symptoms in children exposed to petrochemical pollution. J Allergy Clin Immunol 2009;123:632-8.

18 Barraza-Villarreal A, Escamilla-Nunez MC, Hernandez-Cadena L, et al. Elemental carbon exposure and lung function in schoolchildren from Mexico City. Eur Respir J. 2011;38:548-52.

19 Quanjer PH, Stanojevic S, Stocks J, et al. Ip MSM on behalf of the Global Lungs Initiative. Changes in the $\mathrm{FEV}_{1} / \mathrm{FVC}$ ratio during childhood and adolescence: an intercontinental study. Eur Respir $J$ 2010;36:1391-9.

20 Joseph Bowen J, de Klerk N, Firth M, et al. Lung function, bronchial responsiveness and asthma in a community cohort of 6-year-old children. Am J Respir Crit Care Med 2004;169:850-4. 